\title{
Influence of Grain Shape in Grinding Wheels on the Machining Quality of Bearing Rings
}

\author{
Alexander Korotkov ${ }^{1, a^{*}}$, Vitaly Korotkov ${ }^{1}$ and Nikolay Prokaev ${ }^{1}$ \\ ${ }^{1}$ T.F. Gorbachev Kuzbass State Technical University, Chair of Metal-Cutting Machines and \\ Tools, 28 Vesennyaya str., Kemerovo, Russian Federation, 650000 \\ akorotkov.a.n@mail.ru
}

Keywords: Shape of Abrasive Grains, Shape Factor, Grinding of Bearing Rings, Evaluation of Microstructure, Microhardness, Roughness of Machined Surfaces, Increasing the Resistance of Grinding Wheels

\begin{abstract}
The quality of grinding of bearing races is related to their performance and durability. The aim of this work is to establish how the machining quality of bearing rings depends on the characteristics of grinding wheels, in particular, on such a parameter as the shape of abrasive grains. Several batches of experimental grinding wheels were made, containing grains of different shapes (from isometric to lamellar varieties). Quantitatively, the shape of the grains was estimated by the shape factor parameter $\left(\mathrm{S}_{\mathrm{F}}\right)$, which is equal to the ratio of the diameters of inscribed and circumscribed circles in the contours of the used grains. The shape factor was determined using a scanner or a digital microscope and a special computer program. The tests were carried out on circular, plunge, and finishing grinding, using coolant, on a SIW 4E machine in a bearing factory. The machining quality of the bearing rings was assessed by studying the microstructure, microhardness and roughness of their bearing races. The durability of grinding wheels was determined by the number of machined rings before maximum tool wear. It has been established that by a differentiated approach to the choice of grain shapes in the wheel, it is possible to significantly increase its operational capabilities: increase the microhardness of the ground surfaces, reduce the roughness of processing, and increase the durability of grinding wheels.
\end{abstract}

\section{Introduction}

High requirements are imposed on rolling bearings, since performance of the units and mechanisms where they are used depends on their quality. Requirements are made for static and dynamic strength, quality of the material from which they are made, quality of heat treatment, as well as condition of their working surfaces - roughness and processing accuracy, presence of defects in the surface layers of the metal. In the case of insufficiently high quality of the tool during grinding process, burns, increased roughness of the machined surfaces and a small number of machined parts (low tool life) are possible. Reliability and durability of operation largely depends on the condition of surfaces of rolling bearings, therefore it is important to know what factors and to what extent affect formation of the quality of these surfaces.

This work is aimed at studying the quality of the machined surfaces of bearing rings made of heathardened 52100 steel (ANSI) after fine grinding with experimental wheels with a controlled grain shape [1]. The wheels were made according to the standard technology for ceramic-bonded tools. They included mixtures of clay, feldspar, pegmatine, boron glass, talc and other materials [2]. A distinctive feature of the wheels was the presence in their composition of abrasive grains of white electrocorundum (25A), which have a different shape [3]. To obtain such grains, the initial mass of free abrasive was subjected to separation on a vibrating separator into a number of fractions with different shape factors $\left(\mathrm{S}_{\mathrm{F}}\right)$ [4]. The separation of 
grains was carried out on a vibrating inclined plane (vibrodeck), where they were poured in a laminar flow into the upper part of the deck and scattered along it in a diverging fan, depending on their shape (coefficient of friction of grains with the deck) [5]. The abrasive collected in the lower part of the deck was used further for manufacture of experimental grinding wheels according to the standard technology. In this way, six batches of grinding wheels were made with grains of different shapes in their composition. As an objective parameter for the quantitative assessment of the grain shape, we used the shape factor $\left(\mathrm{S}_{\mathrm{F}}\right)$ equal to the ratio of the diameters described and inscribed in the contours of individual grains and circles. At least one hundred measurements were carried out for each grain fraction; the obtained coefficients were averaged and the average shape factor was formed, which characterized the shape of the grains of this fraction $[6,7]$. The manufactured batches of experimental grinding wheels had the following shape factors: $\mathrm{S}_{\mathrm{F} 1}=1.19$, $\mathrm{S}_{\mathrm{F} 2}=1.51, \mathrm{~S}_{\mathrm{F} 3}=1.7$ (standard wheels from unsorted grains), $\mathrm{S}_{\mathrm{F} 4}=2.4, \mathrm{~S}_{\mathrm{F} 5}=2.39, \mathrm{~S}_{\mathrm{F} 6}=2.88$.

The closer the $\mathrm{S}_{\mathrm{F}}$ value is to 1.0, the more grains in such wheels approach the isometric shape, and the more significantly $\mathrm{S}_{\mathrm{F}}$ differs from 1.0, the more grains correspond to the lamellar varieties.

The experimental wheels were tested on circular, plunge, and fine grinding of the bearing races of the outer rings of bearings (307 and 205) in a bearing plant on a SIW 4E machine [8,9].

\section{Methodology for preparing and conducting tests.}

In the manufacture of experimental wheels, all necessary operations were sequentially performed: preparation of a mixture of grains with a binder in accordance with the required structure, molding of wheels and their firing at a temperature of $1280{ }^{\circ} \mathrm{C}$, followed by sulfurization. Along with the listed actions, an operation was added to sort the initial mass of abrasive into a number of fractions with the same grain shape. During wheel manufacture, their visual and dimensional control was carried out (Russian standard GOST 2424-83), as well as control of their hardness after firing (GOST 25961-83).

As a result, the experimental wheels produced had the following characteristics:

Type1 63x12x16 25A F120 [S $]$ K 5 V;

Type1 40x7x6 25A F120 [SF] K 5 V,

where $\left[\mathrm{S}_{\mathrm{F}}\right]$ is the grain shape factor, which varied discretely in different batches of wheels in the range from 1.19 to 2.88 ;

The bearing rings to be machined were made of heat-hardened 52100 steel (ANSI). They were hardened, followed by low tempering to a maximum hardness of HRC 64-66. Cutting modes for grinding rings were selected in accordance with the recommendations for this type of processing and had the following parameters: $\mathrm{t}=0.173 \mathrm{~mm}, \mathrm{~S}_{\text {fine }}=0.12 \mathrm{~mm} / \mathrm{min}, \mathrm{V}_{\text {cut }}=50 \mathrm{~m} / \mathrm{s}$ [10]. Grinding was carried out using coolant. When using the plunge-in method (without longitudinal feed), after each machined ring, the experimental abrasive wheel was straightened with a diamond pencil in order to restore the required tool profile, corresponding to the cross-sectional profile of the bearing ring race.

To automate the process of measuring the shape factor on each individual grain, a specially developed computer program was used, according to which the inscribing and describing the circles in the contours of the grains was carried out by a computer using a scanner, and for fine grain sizes - by a digital microscope [11].

\section{Test results}

The results of studying the microstructure and roughness of the surfaces of the bearing races after grinding with wheels having different grain shapes are shown in Fig. 1, Fig. 2, Fig. 3 and Fig. 4 $[12,13]$. 


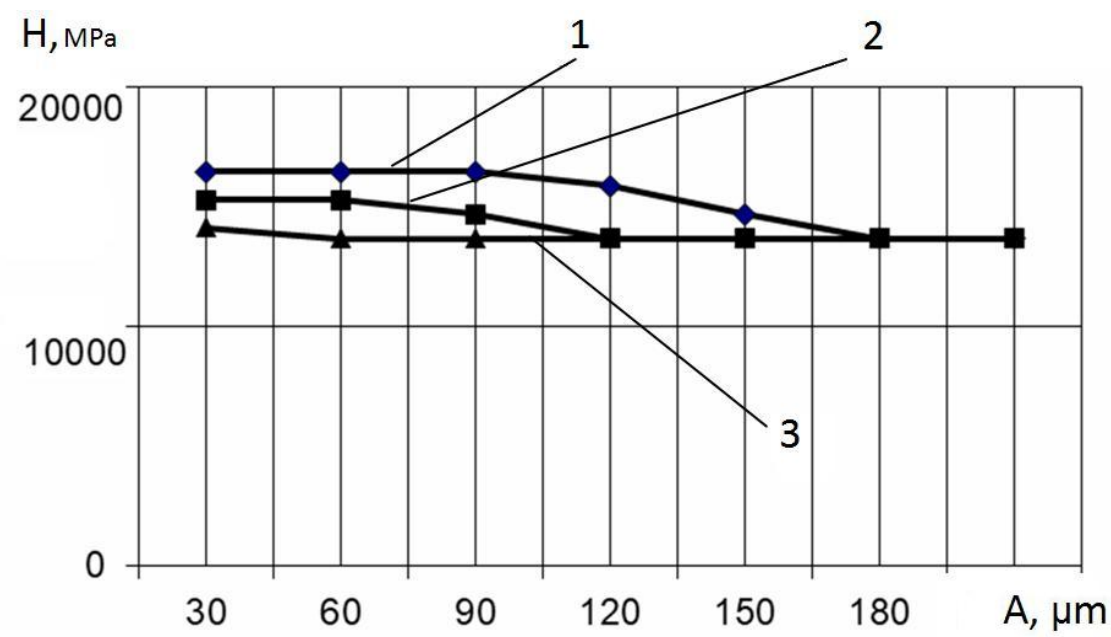

Fig. 1. Distribution of microhardness $(H, M P a)$ on the ground surface of the bearing race inside the part to the depth $(A)$ : 1-wheel $S_{F}=1.19 ; 2$-wheel $S_{F}=1.51$, 3-standard wheel $S_{F}=1.70$.

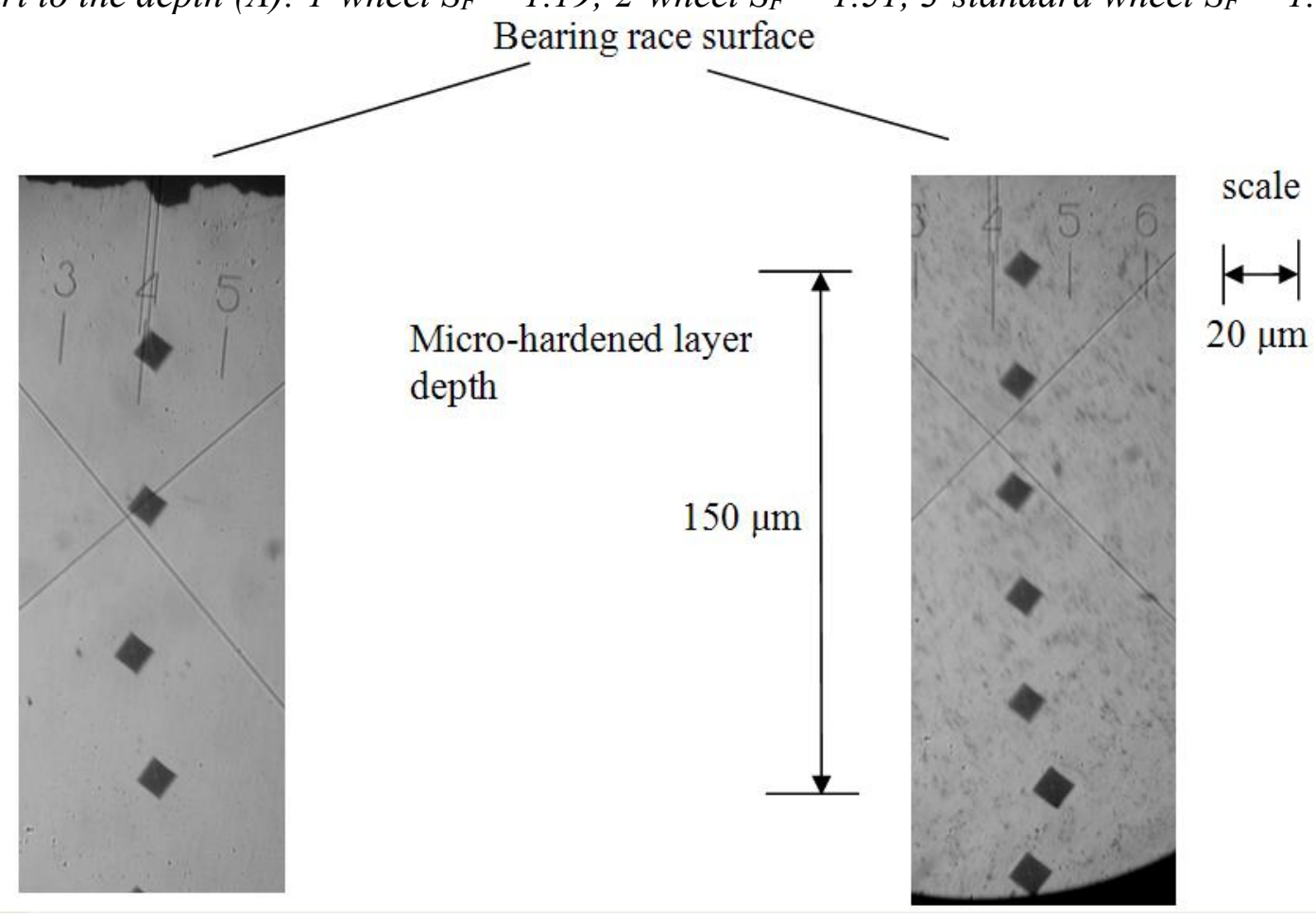

a)

b)

Fig. 2. Distribution of microhardness in the surface layer of 307 bearing race after wheel processing: a) Typel 63x12x16 25A F120 [ $\left.S_{F}\right] \mathrm{K} 5 \mathrm{~V}$ [standard wheel, $\left.S_{F}=1.70\right]$; b) Type1 $63 \times 12 \times 1625 \mathrm{~A} \mathrm{F120}\left[\mathrm{S}_{F}\right] \mathrm{K} 5 \mathrm{~V}\left[\mathrm{~S}_{F}=1.19\right]$.

The graph in Fig. 1 shows that the shape of the grains in the wheel significantly affects the microhardness of the treated surface. Thus, changing the value of the shape factor $\mathrm{S}_{\mathrm{F}}$ from 1.70 (standard wheel) to $\mathrm{S}_{\mathrm{F}}=$ 1.19 , it is possible to increase the microhardness of the ground surfaces of bearing rings 305 and 205 from $13500 \mathrm{MPa}$ to $16500 \mathrm{MPa}[14]$. 


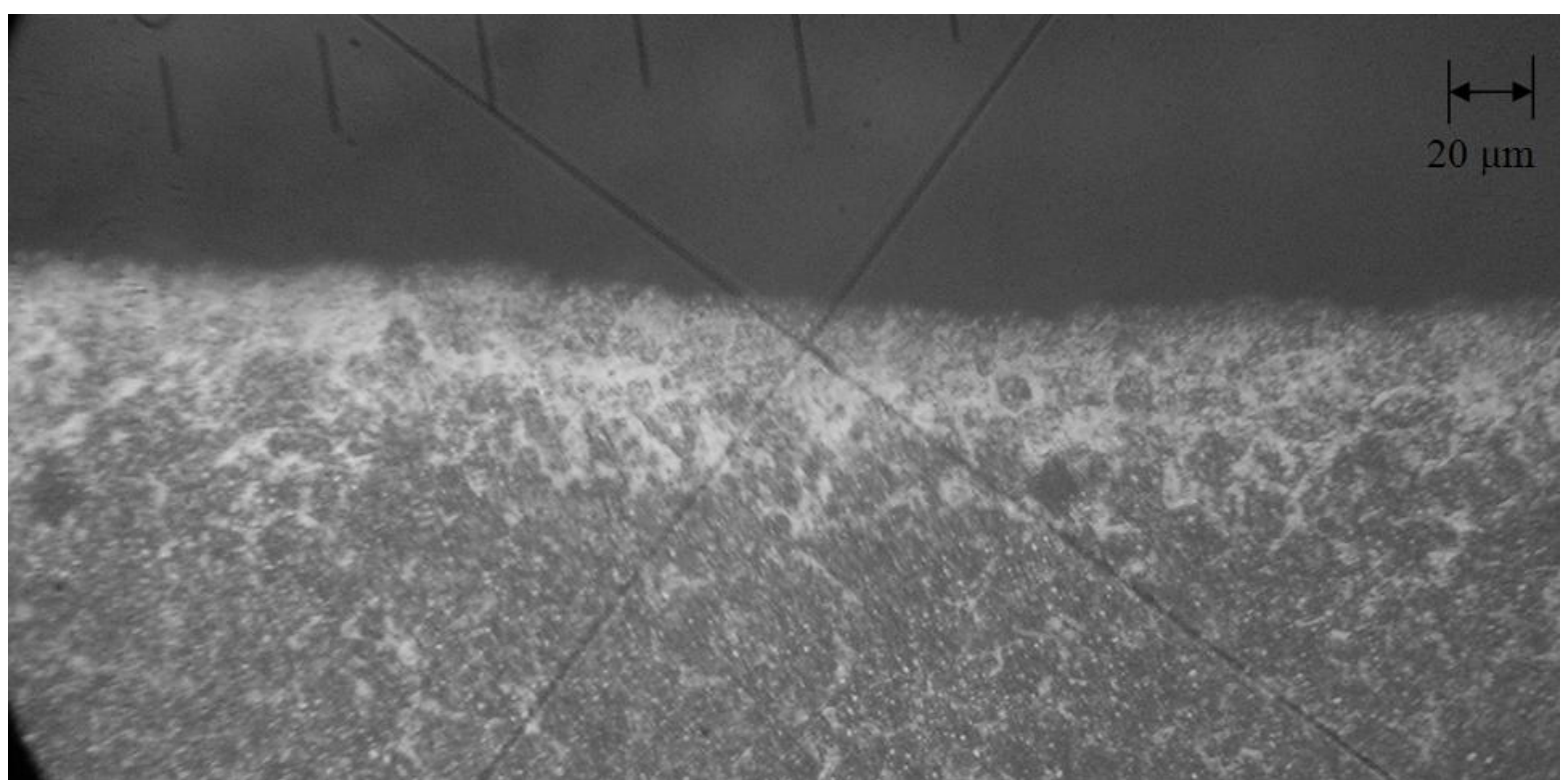

Fig. 3. The microstructure of 307 bearing race after grinding with Typel 63x12x16 25A F120 [S $]$

K 5 V (magnification $\times 500)$

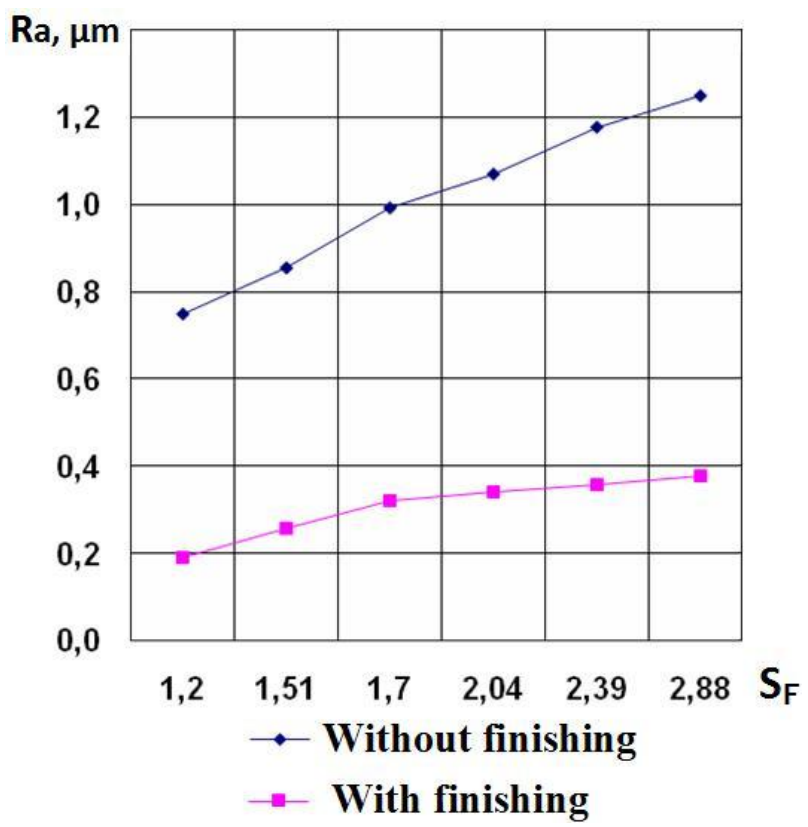

Fig. 4. Influence of the grain shape in a wheel $\left(S_{F}=1.19 ; S_{F}=1.51 ; S_{F}=1.7 ; S_{F}=2.04 ; S_{F}=\right.$ 2.39; $\left.S_{F}=2.88\right)$ on the roughness $(R a, \mu m)$ of the bearing races of the outer ring of bearing 307 (grinding wheels Type1 63x12x16 25A F120 [SF] K 5 V)

The durability of experimental wheels was assessed by a quantitative indicator - the number of ground rings in one experimental wheel up to the maximum wear determined by the machine control system.

The results of resistance tests are shown in Fig. 5, from which it can be seen that about 20\% more rings were processed by wheels with isometric grains $\left(\mathrm{S}_{\mathrm{F}}=1.19\right)$ compared to standard wheels $\left(\mathrm{S}_{\mathrm{F}}=1.7\right)$. Grinding wheels with lamellar grains $\left(\mathrm{S}_{\mathrm{F}}=2.88\right)$, on the contrary, grinded about $15 \%$ fewer bearing rings compared to standard wheels. 


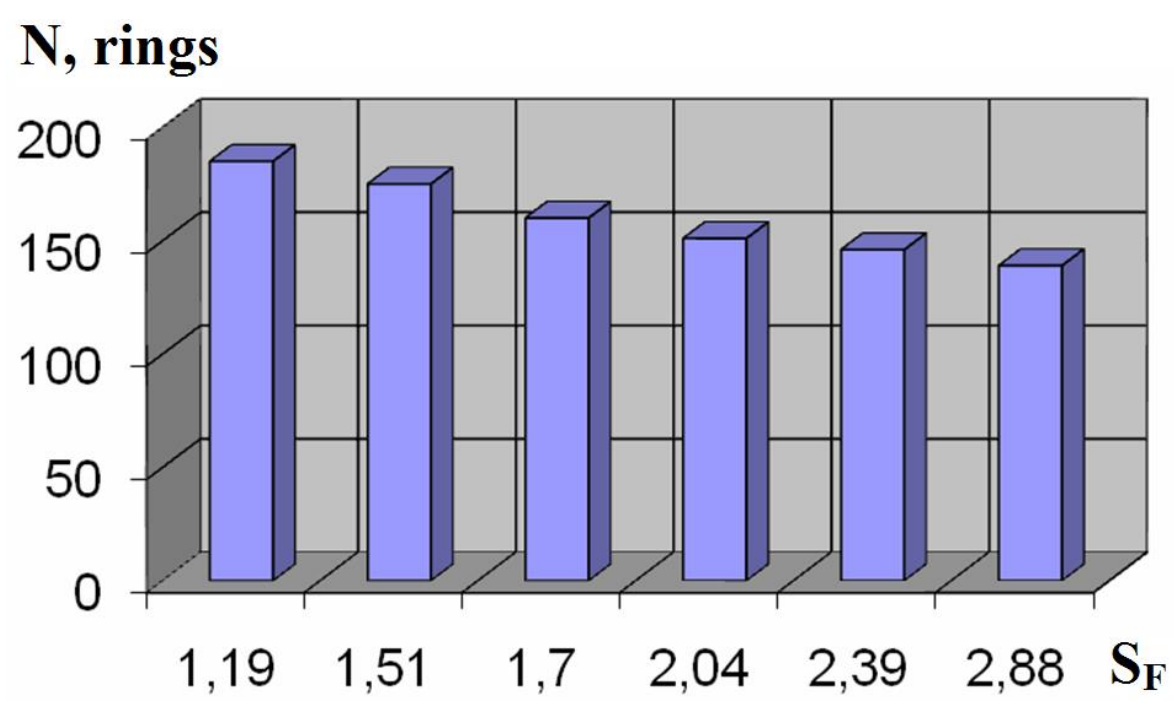

Fig. 5. Number of ground rings (up to the specified dimensional wear of the wheel) depending on the shape factor of the grains in the wheel

In addition to resistance tests, the quality of the treated surface was assessed. It was controlled by the following parameters - waviness, facetedness, roughness, microhardness of the polished surface, microstructure of the polished metal, and the presence of burns [15].

Studies have shown the possibility of improving the machined surface quality of bearing races. Thus, deliberately changing the shape of abrasive grains in the wheel, it was possible to reduce the roughness of the ground surfaces by about $43 \%$ (without preliminary aging) when processing with isometric grain wheels $\left(\mathrm{S}_{\mathrm{F}}=1.19\right)$.In this case, the phenomenon of cold hardening was observed in the surface layers of parts at a depth of $150 \mu \mathrm{m}$, accompanied by an increase in microhardness from $14000 \mathrm{MPa}$ to $16500 \mathrm{MPa}$ (by 20\%). Due to low temperature in the surface layers of parts, burns and other changes in the structure associated with decomposition of the structure of hardened steel - martensite were not revealed. As for macrofactors - waviness and facetedness, the negative influence of the shape factor in this case was not revealed.

\section{Conclusions}

In general, studies have shown that by purposefully selecting the shape of abrasive grains, it is possible to improve the quality of processing products by significantly reducing the roughness of the processed surface (up to $43 \%$ ), increasing the microhardness of the ground surface (up to $22 \%$ ). At the same time, the service life of the grinding tool can be increased (by $20 \%$ ). In the future, it is also possible to increase cutting conditions to reduce technological processing time, or it is possible to correct errors obtained as a result of previous operations.

Thus, the use of ceramic-bonded grinding wheels with a differentiated approach to the choice of the grain shape makes it possible to increase the tool life when bearing races of the outer rings of bearings made of heat-hardened 52100 (ANSI) steel. Selection of the grain shape, as shown by tests, in its significance can be comparable to changing the grade of abrasive to a more expensive one or reducing the grain size to a finer one.

\section{References}

[1] Korotkov, A. Improving operational capability of grinding tools: Monograph / KuzSTU Kemerovo, (2005).

[2] Abrasive materials and tools. Catalog (M .: VNIITEMR, 1986) 
[3] Korotkov, A. Operational properties of abrasives: Monograph Publishing House of Krasnoyarsk. University Press, (1992).

[4] Patent. 224885136303 RF MPK7. V07V1/40, 13/007/08. Vibratory separator / Korotkov A., Dubov G. Bashtanov V. № 2003129945; statements. 08. 10. 03; published. 27. 03. 05; Bulletin. № 9.

[5] Taschenbuch Maschinenbau (Verlag Technik Berlin, 1978)

[6] Certificate of official registration of the computer number 2006610153. Shape sanding grains / Korotkov A., Rilov G. № 2005612738; statements. 25. 10. 05, published. 10. 01. 06.

[7] Certificate of official registration of the software for computer №2003611938.

Determination of geometrical characteristics of grinding grains / Korotkov A., Zakharov D. № 2003611454; statements. 2. 07. 03; published. 22.08. 03.

[8] A.Hirsch, Werkzeugmaschinen. Grundlagen, Viewegs Fachbuecher der Technik (2000). https://doi.org/10.1007/978-3-322-93837-4

[9] Verein Deutscher Werkzeugmaschinenfabriken e. V. (Hrsg.): Werkzeugmaschinen

Bezugsquellenverzeichnis, (Ausgabe, Frankfurt am Main, 1997)

[10] Handbuch der Metallbearbeitung (Verlag Europa-Lehrmittel, 2000)

[11] Certificate of official registration of the software for computer №2006613051. Form sanding grains in volume / Korotkov V., G. Rilov, № 2006612327; statements 04/07/06, published. 1. 09. 06

[12] E. Berghof-Hasselbächer, Atlas of Microstructures (DGRT, Berlin, 2013)

[13] G. Zlateva, Microstructure of Metals and Alloys: An Atlas of Transmission Electron Microscopy Images (Taylor\&Francis Group, London, 2008).

https://doi.org/10.1201/9781420075571

[14]B. Bramfitt, Metallographer's Guide: Practices and Procedures for Irons and Steels (ASM International, Manchester, 2002). https://doi.org/10.31399/asm.tb.mgppis.9781627082587

[15] Degner W., Lutze H., Smejkal E. Spanende Formung: Theorie, Berechnung, Richtwerte, (Carl Hanser Verlag Muenchen Wien,1993) 